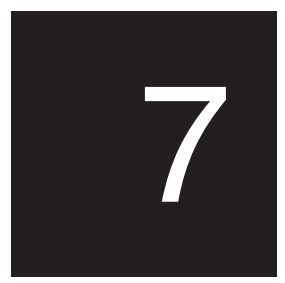

\title{
Knowing about culture: the handling of social issues at resource projects in Papua New Guinea
}

\section{John Burton}

Ethnography is a controversial activity when applied to development issues, notably the 'mineral policy process' in Papua New Guinea. This chapter concerns the kind of development where huge investments are involved - the Papua New Guinea minerals sector has been worth K2.2-2.4 billion in the last few years. The minimal view presented is that investors with hundreds of millions of kina to risk should adopt the precautionary principle of doing the best social impact appraisals they can, and continue to evaluate their own performance in relation to social issues and impact for the length of the mining projects. This is a minimal view: hopefully developers would wish to do considerably more than this and have corporate policies placing culturally appropriate management techniques in a more central position, but it is not necessary to my argument.

Within the mining industry, the kinds of skills and knowledge to handle social issues have been referred to as the 'new competencies' of mining, the 'soft skills that are, in fact, hard skills' as a landmark speech from the chairman of CRA described them (Davis 1995). At the level of executive corporate policy statements, other major resource 
companies echo this sentiment, with frequent reference to the concept of 'world's best practice in environmental care'.

The importance of sociocultural research is that in this narrow context, using suitably appropriate ethnographic techniques and inventing new ones where necessary can avoid risk for both investors and local communities. A loftier ambition is to head off more serious political crisis, such as occurred in Bougainville and more recently at Ok Tedi. Unfortunately, attainment of the 'new competencies' leaves much to be desired.

\section{Mine impact studies in Papua New Guinea after Bougainville}

In September 1989 at a Bougainville crisis workshop held at the University of Papua New Guinea, I commented that little research into the land and social organisational matters that sparked the Bougainville crisis was carried out prior to the opening of the mine, and no studies were done afterwards. Further, sustained fieldworkintensive studies were not being carried out in any of the new mining areas. I called for a reprioritisation of funding arrangements for applied social research in Papua New Guinea (Burton 1989).

Nothing meaningful eventuated from the workshop, although many prominent Bougainvilleans attended, including the now rebelaligned Premier Joseph Kabui. It was also ironic that institutional research funds were cut to nothing in the following budget year as part of the government's austerity measures.

A turning-point for mine impact studies in 1989 was a seminar given at the University of Papua New Guinea (UPNG) by Stuart Kirsch, a doctoral student in anthropology then returning from a long stay among the Yonggom people. Kirsch was able to detail at first hand the issues which were, five years later, to lead a group of Yonggom spokesmen to instigate law-suits in the Supreme Court of Victoria, in Melbourne, seeking reparations of $\mathrm{A} \$ 4$ billion for environmental damage. The seminar and its subsequent publication, notably in the Times of Papua New Guinea under the headline 'Ok Tedi a sewer' (Kirsch 1989a; 1989b), was treated by the mine operators and government officials as nuisance academic commentary. Photocopies of Kirsch's second article, published a little later in Research in Melanesia, circulated among the mining management in Tabubil and Port Moresby during 1990 and 1991, at the same time as the Papua 
New Guinea government approved the Sixth Supplemental Agreement at Ok Tedi, which allowed, after three years of environmental studies, the permanent discharge of mine wastes into the Ok Tedi and Fly River systems.

In respect of Ok Tedi, a decade earlier, Richard Jackson (and his student Budai Tapari), were seconded to Papua New Guinea's National Planning Office for six months to do a planning study of the North Fly area, where the mine was then being negotiated. However, after the mine opened Jackson was only able to find a few thousand dollars for follow-up studies, and monitoring of the social environment ceased in 1984. Throughout the 1980s, starved of institutional funds, with intermittent international grants, and with a weak ability to market its expertise, mine monitoring work from the University of Papua New Guinea was limited to the environmental investigations in water bodies off the Fly River more than $250 \mathrm{~km}$ from the mine site (Pernetta 1988).

\section{Ok Tedi}

From about 1990, consultancy work at UPNG received much stronger support from an administration keen to bring income to the university. A new program of company-sponsored social monitoring studies began in mid 1991 at Ok Tedi, focusing on the downstream communities, including those in the Lower Ok Tedi where Yonggom and Awin villagers were taking the brunt of environmental problems after the signing of the Sixth Supplemental Agreement.

The Alice villagers lodged writs in Australia in 1994 and, after two years of legal argument costing an estimated A\$20 million, secured an out-of-court settlement with the company comprising various compensation packages worth about A \$100 million to the year 2010 . The company is committed to a river dredging trial costing A $\$ 60$ million to the end of 1998 and will adopt further clean-up schemes after this, costed at a further several hundred million dollars.

How then should the spectacular success of the plaintiffs in the law suit be seen? First, it is worth bearing in mind that the litigation could not have been launched in the absence of a law firm prepared to carry its expenses until a settlement had been reached, and to write them off if it lost. The assistance of international NGOs, for example in extending invitations to meetings in Holland, Germany and Canada, was extremely important in helping the two principal actors, Rex Dagi 
and Alex Maun, reshape and express their ideas in the forms that would be most efficacious in attracting and keeping hold of international attention.

Nevertheless, the key may be that much of their success was due, not to the surmounting of traditional culture-for example, to form wider, stronger neighbourhood alliances or to make use of modern legal tactics-but from its use of traditional culture to resist being suborned by partisan political power and the intense pressure brought to bear on them by their adversaries. At the height of the crisis, for example, the national government passed the Prevention of Foreign Legal Proceedings Act just to outlaw the efforts of Dagi, Maun, and their less well-known associates Moses Oti and Robin Mokin, to seek redress in the courts. Kirsch reveals that the four were members of the same kaget won, or initiation cohort, some twenty years ago, and thus were not susceptible to wavering or division. This was not true of the interest block formed by the affected Alice villages in the course of the political process; a split emerged during the crisis between the east bank Awins and the west bank Yonggoms led by Dagi and Maun. Nor was there ever a rapprochement between the downstream Alice people and the Faiwol and Wopkaimin mine-lease landowners of the Star Mountains, who watched the litigation crisis with only the concern of rentiers concerned that their source of income would be cut off were the mine to close.

How did our social monitoring reports fit in? Could it be that we were instrumental in effecting a turnabout in the handling of the downstream landowners and of compensation claims along the Alice? An internal company document Strategic Plan-Social Issues dating from late 1992 attempted to rank risks to the company's operations mentioned our program in the following terms: 'The impact of development on the social structure of the people in the region is currently under study by anthropologists. Ranking-problems arising from the introduction of the new cultures are viewed as presenting a relatively low long-term threat to Ok Tedi [my emphasis]'.

Unfortunately, the rather quaint thought that we were studying the 'impact of development on the social structure of the people' failed to reflect the content of our (or anyone else's) reports. It is not surprising that a low risk assessment was made, given that the organisation lacked the ability to process messages carrying tell-tale warning signs that may have been received from time to time, either from our 
specialist reports or from the company's own field officers. A case in point is my re-discovery in 1997 of internal documents showing that a junior staffer had visited the Yonggom village of Dome in late 1988 and had reported to his superiors in detail the petition that later became the basis of the 1994 writs. His report was 'lost' to management by becoming buried in internal departmental files.

The signs that we and the key decision-makers did not share the same language and were not able to communicate properly were the least of our worries. We came to realise that one section of company management had hired us to stir another section-asleep at the helm in spite of Bougainville-into action. The first of our results, showing the seriousness of damage to land, crops and bush resources-and the extremely high risk of procrastination-appeared three years before the lawsuit started. Unfortunately, all twelve of our reports were denied to the company's Community Relations officers from 1991 to 1996 highlighting our overall ineffectiveness. Our creation of knowledge at the behest of the company was politically neutralised by forces within the company that were beyond our reach.

Misconceptions which were beyond our ability to control also sprang up. I remember a question from a senior official asking whether or not enquiries at village level provoked the political activism we were hired to assess and advise the company on. It seemed a common conviction. Logically it betrayed a raft of illarticulated beliefs (a) that villagers possessed no independent powers of observation (b) that ethnographers are fumbling naifs easily misled by tricksters or, alternatively (c) that they have amazing superpowers enabling them to 'plant' misleading information on gullible villagers.

The mining industry was willing to spend money on monitoring of the physical environment but unable to understand and draw up policies for the social environment. In Ok Tedi's case, company expenditure on environmental monitoring in the decade after the opening of the mine amounted to over $\mathrm{K} 50$ million, but barely $\mathrm{K} 0.5$ million on social monitoring. This amounts to a spending ratio of about 100:1.

Despite this, some basic answers about the workings of the river system were not forthcoming from the scientific program. Two key examples were its inability to explain the unrelenting decline of fish biomass in the river system, below levels predicted in the studies used by government to authorise riverine tailings discharge; and the faulty computer models that led to the assertion that sediment build-up in 
the Middle Fly would be negligible, also taken into account in the government's decision. In the latter case, villagers were adamant in 1994 that the build-up of mine wastes was blocking their canoe passages and lagoon entrances. They were right; a re-study published in 1996 finally showed 2 metres of river bed aggradation, now modelled to rise to $3.5-4.5$ metres in future years.

\section{Porgera}

At Porgera, in the Papua New Guinea highlands, an unprecedented level of economic benefits has flowed to the community: housing for over 500 families, about K60 million in business contracts, about K30 million in compensation for land clearance, and sundry other benefits, including mine employment for about eight hundred (Banks 1997). At the same time staff deployed in community relations functions has grown to about 85 people across the Enga Province, a far greater number than had ever been used in any other resource project in the country (Bonnell 1994:112).

The Porgerans invented what is termed the 'Development Forum': a series of round-table meetings in which the would-be developers, in this case Placer, and the various levels of government respond to a position paper presented by landowner representatives. The invention of the Forum reflects a substantially greater level of activism on the part of Porgera leaders; unlike the Faiwol, Awin and Yonggom, their society supplies a political style of leadership.

The other side of the story is the question of who has received this substantial income and what problems of distribution, so notorious in contributing to the cause of the Bougainville crisis have arisen (Filer 1990). I recently reviewed the ways in which company management at Porgera has sought to acquire knowledge about the social impact on the Ipili, the ethnic group surrounding the mine at Porgera (Burton n.d.). The Environmental Management and Monitoring Plan (EMMP), an essential part of the documentation required for mine approvals, noted the establishment of a socioeconomic liaison committee in 1991 (Porgera Joint Venture 1991:para 8.13). However, two years elapsed before this committee held a meeting, chaired by an official of the Department of the Environment and Conservation, the relevant government regulatory body. This meeting set my colleagues and I the task of writing a plan for what was termed the 'Porgera Social Monitoring Program', completed in June 1993 (Burton et al. 1993). 
Since our document was laboriously put together by consulting with the other parties to the committee and building from earlier documents that had dealt with similar issues, it was unlikely to have been technically defective. At least, no other party responded by saying so, however-no other party responded at all! The state regulator proved incapable of effective comment because of the conflict of interest arising from the government's financial involvement in mining (Bonnell 1994:118).

A series of monitoring reports was produced over an eighteen month period in 1993-94 (for example, Banks 1994; Bonnell 1994), but the program lapsed thereafter.

Two conclusions are notable here. The first is that although the company had a large community relations staff, only a handful were in managerial positions and perhaps only two or three incumbents held tertiary qualifications, none at higher than bachelor degree or diploma level. Outside Porgera, in particular, the numbers are made up of assistants with a typical Grade 6-10 education. This means that their ability to make basic investigations at community level was extremely limited; even if information were collected, no member of staff had the time to analyse it or to write policy documents of greaterthan-memo length.

The second conclusion is that the patterns of secondary distribution and investment of compensation money remain unknown, as systematic research to find this out has not been done. There are grounds for suspecting the compensation passed from the company to the community without sufficient measures to protect the latter's weaker members, such as women, infants, the aged, the children of single mothers, and people absent during assessments, such as those working outside the province. Documentation for a payment of K100,880 for clearance of an eight hectare land block shows members of a family received amounts ranging from K25,220 down to K140 (Department of Enga 1992). The beneficiary of the smallest amount, an infant, received $1 / 180$ th of the recipient of the greatest amount, a senior man. Does this mean that of the land compensated for, in adulthood the infant will be satisfied with only $1 / 180$ th of its inheritance? No, such a thing is ridiculous. Both company and provincial lands officers declined to use available legislation, such as the Land Groups Incorporation Act, to maximise fairness and accountability in decision-making over the pay-outs. 
Even if suspicions of this nature are waved away, since the Porgera mine entered production in 1990, annual compliance reports for the Department of Environment and Conservation, mandatory under government guidelines, have not been submitted in respect of social impacts. Even if the activity reports of 1993 and 1994 count as compliance, this still leaves five years out of seven, 1990-96, with none submitted. If the Department of Environment and Conservation never asks for such reports, forgets to ask for them, or cannot read them if they are provided, the principle of best practice insists that a modern company acts as if it does. There is no excuse for failing in this; equally seriously, shareholders should be alarmed when any company fails to make a proper account of its activities to them. My full arguments run to some length, but assert that the company has blindfolded itself by failing to collect the kinds of knowledge that it requires to head off a serious crisis, a repetition of Ok Tedi's example.

\section{Lihir}

The Lihir mine in the New Ireland Province began production in 1997. In this case the current operator, Rio Tinto, adopted the objectively 'worst practice' of buying the prospect from another company, Kennecott, complete with a time-expired social impact study-and did not update it or attend to the limitations pointed out at the time.

[Our report is limited by] the absence of any substantial documentation of Lihir society by anthropologists or other writers who have spent long periods of time there... research conducted on a 'fly-in-fly-out' basis can only produce particular kinds of information, and cannot do more than scratch the surface of village society (Filer and Jackson 1989:2).

A social impact review was finally ordered by the Australian government's Export Finance Insurance Corporation (EFIC) as a condition of loan guarantees-but the review was confidential to EFIC, an unacceptable practice in our field. In the 50 page summary 'Environmental Plan' (EP), the social environment is dealt with in just three paragraphs.

Lihir landowners bettered their Porgeran brethren with still more generous compensation and royalty provisions, 12.35 per cent equity in Lihir Gold which may eventually be worth a couple of hundred million dollars, and a seat on the board. 
In Australia, political conservatives claim uncertainty over native title poses a threat to the development of resources. At Lihir a preliminary understanding to proceed with mining was signed in 1984. It established the ownership of different clans of the approximately 600 hectares between the two principal creeks of the Luise Caldera. By 1995 when final approvals were granted, a little over half of the area changed hands following rulings in the Provincial Lands Court or was subject to ongoing litigation between customary owners. This is a clear example of 'uncertainty over native title'. When Lihir Gold was floated on the Sydney Stock Exchange in mid-year, it was not thought significant to mention this in the share prospectus, a serious non-disclosure.

The compensation and royalty provisions are generous, but insufficient measures have been taken to give a correspondingly greater level of accountability to their distribution. I have no doubt at all that complaints based on this will emerge in Lihir in years to come.

\section{Conclusions}

While my colleagues and I have certainly been able to generate a lot more information in the 1990s than in the 1980s, we have not been capable of prompting lasting reform within the corporations. In each instance, the companies are industry leaders-BHP, Placer and Rio Tinto- and each espouses best practice principles at the level of boardroom. At the 'coalface', that is to say at the middle management levels where their organisations interact with the village societies hosting their projects, these ideals are discarded and a reversion to type occurs.

What is this 'type'? I recently described what I called the 'discovery' paradigm, a package of concepts validating the enterprises of geological exploration and mining in-using the paradigm's own words-'remote' areas of the world (Burton 1997). The mission statement for the discovery paradigm, was Forbes Wilson's 1981 book The Conquest of Copper Mountain, about the discovery of the Freeport mine in Irian Jaya. Wilson described the overcoming of apparently insurmountable physical obstacles in 'the mountainous interior of the world's most trackless wilderness' (Wilson 1981:10). An additive is the cliché 'remote', still making almost daily appearances in miningrelated literature on Papua New Guinea and seen in press reports such as 'the Ok Tedi project, on a mountain's edge in the remote... highlands of Papua New Guinea', which appeared in The Sydney 
Morning Herald on the day the Ok Tedi court settlement was announced. I added the companion concept of terra nugax, which has one meaning of land that, not being used for anything else, or having 'trifling other uses', is a promising candidate for mineral extraction, and the fulfilment of national developmental goals through the exploitation of nationally appropriated resources.

But is this not a cultural landscape populated by tribes and customary landowners? Unfortunately, the qualities of being 'remote' and 'undiscovered', in the special sense of not having had a mining industry culture hero traverse the landscape, brings a second and key meaning to terra nugax; land that, though it is 'of someone', lies untouched by the political process of metropolitan society: it is invisible to the politically empowered citizenry of that society. The political connections of this land are believed 'trifling, of no consequence, nugatory' and that decisions can happily be made about it with few repercussions.

These attitudes centralise the metropolitan actors thought to be the 'real' political players and relegate the resident societies to being peripheral. Since they are all 'much the same', the ethnographer, whose job is often about difference and diversity, is out of work, or at best occupies an ornamental position. When our work closes in on something of real importance, as it occasionally does, we typically find ourselves, ostensibly the holders of key areas of knowledge, side-lined or neutralised.

However, the outcome of the Ok Tedi litigation, the extremely favourable compensation and royalty packages negotiated at Lihir and Porgera destroy the fundamental assumptions of the discovery paradigm, namely that the political connections of terra nugax to metropolitan political structures are not 'trifling, of no consequence, nugatory'. In fact they are extraordinarily powerful. In all of these examples, indigenous interest groups easily matched or surpassed both central government and the largest corporations in the court room and at the bargaining table.

Is what I have described about culture or about politics? 'Culture' is often discussed as a kind of thing separated from political affairs, governance, business and development. In Papua New Guinea, miners, often encouraged by government agencies, have consistently faced problems by believing that culture is something people put on with the feathers and paint they dance with. In Papua New Guinea, politics, whether inside the men's house or out on the hustings, is 
culture. Landowner representatives who bargain harder than others are doing it because their culture supplies them with better tools to do so- they are using their culture to elevate their profile as stakeholders.

It is frustrating to find that the thorough analysis of social issuesdespite the sobering experiences of Bougainville and Ok Tedi-still has no more than an ephemeral, discontinuously-funded presence in the management structures of the resource companies. The 'new competencies' of mining may have been heralded by their chief executives, but they are definitely still to take root lower down their organisations.

\section{Acknowledgments}

I owe a debt to many, among academic colleagues, the mining industry, as well as in village communities. Let me thank them as a whole and apologise to any on whom critical comments, intended constructively, impinge.

\section{References}

Applied Geology Associates, 1989. Environmental, Socio-economic and Public Health Review of Bougainville Copper Mine, Panguna, A report for Bougainville Copper Limited, Wellington.

Banks, G.A., 1994. Porgera Business Study, PSMP Report No.5, Unisearch PNG Pty Ltd for Porgera Joint Venture, Port Moresby.

,- 1997 . Mountain of desire: mining company and indigenous community at the Porgera Gold Mine, Papua New Guinea, PhD thesis, The Australian National University, Canberra.

Bonnell, S., 1994. Dilemmas of Development: Social Change in Porgera 1989-93, PSMP Report No.4, Subada Consulting for Porgera Joint Venture, Thornlands.

Burton, J. E., 1989. The land tenure system of the Nasioi people, and the bare cupboard of sustained research in mining areas, Paper presented at Bougainville Crisis Workshop, University of Papua New Guinea, September 1989 (unpublished).

—, 1991. The Ningerum LGC Area, Ok-Fly Social Monitoring Project Report No. 2, Unisearch PNG Pty Ltd, Port Moresby.

, 1993. Development in the North Fly and Ningerum-Awin Area Study, Ok-Fly Social Monitoring Project Report No. 6, Unisearch PNG Pty Ltd Pacific Social Mapping, Port Moresby and Canberra. 
_ ' Knowing the Ipili: evidence of the 'new competencies' at the Porgera gold mine', in C. Filer (ed.), Social monitoring at Porgera, National Research Institute, Port Moresby (forthcoming).

— 1997. 'Terra nugax and the discovery paradigm: how Ok Tedi was shaped by the way it was found and how the rise of political process in the North Fly took the company by surprise' in C. Ballard and G. Banks (eds), The Ok Tedi settlement: issues, outcomes and implications, National Centre for Development Studies and Resource Management in Asia-Pacific, Research School of Pacific and Asian Studies, The Australian National University, Canberra.

Burton, J.E., Filer, C., Banks, G., Bonnell, S., 1993. Porgera Social Monitoring Program: plan and objectives, Unisearch PNG Pty Ltd for Department of Environment and Conservation and Porgera Social Monitoring Steering Committee, Port Moresby.

Corren, A.G., 1989. Compensation for damage to land as a result of mining operations, Papua New Guinea Law Society Conference (unpublished).

Davis, L.A., 1995. New competencies in mining, Paper presented to Australian Institute of Directors, Melbourne (unpublished).

Department of Enga, 1992. Compensation claim [unnumbered], 26 May 1992, Division of District Administration and Mine Site Office, Porgera.

Filer, C., and Jackson, R., 1989. The Social and Economic Impact of a Gold Mine in Lihir. University of Papua New Guinea, Department of Anthropology and Sociology, Port Moresby (revised and expanded).

— 1990. 'The Bougainville rebellion, the mining industry and the process of social disintegration in Papua New Guinea' in R.J. May and M. Spriggs (eds), The Bougainville Crisis, Crawford Press, Bathurst:73-112.

Kirsch, S., 1989a. 'Ok Tedi a sewer', Times of Papua New Guinea, 1 June:3.

— 1989b. The Yonggom, the refugee camps along the border, and the impact of the Ok Tedi mine, Research in Melanesia, 13:30-61.

_ 1993. The Yonggom people of the Ok Tedi and Moian Census Divisions: An area study, Ok-Fly Social Monitoring Project Report No. 5, Unisearch PNG Pty Ltd and Canberra, Pacific Social Mapping, Port Moresby.

_ 1997. 'The Yonggom and the Ok Tedi', in C. Ballard and G. Banks (eds), The Ok Tedi Settlement: issues, outcomes and implications, 
National Centre for Development Studies and Resource Management in Asia-Pacific, Research School of Pacific and Asian Studies, The Australian National University, Canberra.

Momis, J., 1974. 'Taming the Dragon', in P.G. Sack (ed.), Problem of Choice: land in Papua New Guinea's future, Australian National University Press, Canberra:190-99.

Oliver, D., 1991. Black Islanders: a personal perspective of Bougainville, 1937-1991, Hyland House, Canberra.

Pernetta, J.C. (ed.), 1988. Potential Impacts of Mining on the Fly River, UNEP Regional Seas Report and Studies No. 99 and SPREP Topic Review No.33, Nairobi.

Porgera Joint Venture, 1991. Environmental management and monitoring program for Porgera gold mine, Port Moresby, July (unpublished).

Wilson, F., 1981. The Conquest of Copper Mountain, Athenaeum, New York. 